\title{
Clinical, Biochemical and Molecular Characterization of a Cohort of Glycogen Storage Disease Type I Patients in a High Complexity Hospital in Argentina
}

Journal of Inborn Errors of Metabolism \& Screening 2021, Volume 9: e2020002 DOI: https://doi.org/10.1590/2326-4594JIEMS-2020-0028

\author{
Verónica Bindi' ${ }^{1}$, Hernán D. Eiroa ${ }^{1}$, Carolina Crespo², \\ María Martinez ${ }^{1}$ and Luisa Bay ${ }^{1}$
}

\begin{abstract}
Glycogen storage disease type I is an autosomal recessive disorder of carbohydrate metabolism that manifests mainly by hepatomegaly and hypoglycemia with short fasts. Despite strict therapy, patients present long-term renal and liver complications.

Data of 36 patients,29 GSD la and $7 \mathrm{lb}$ from a high complexity Hospital in Argentina was collected retrospectively. Collected data included diagnosis, anthropometric, biochemical parameters, therapy and follow-up.

Treatment increased Height SDS $(p=0.012)$. Patients with good adherence to therapy presented better growth parameters $(p=0.049)$. Instead, admissions were detrimental $(p=0.031)$ and were more common in lb patients $(p=0.002)$. The early appearance of complications (liver adenomas and nephropathy) was related to sustained triglyceride values $>500 \mathrm{mg} / \mathrm{dl}(p=0.009$ and 0.046 respectively).

With intensive dietary treatment, clinical and biochemical status improves but cannot be completely corrected in most patients. Growth improves with treatment and this is optimized with adequate adherence. We must take into account that with ageing, more complications will develop.
\end{abstract}

Keywords: Glycogen storage disease I, growth, metabolic control, Complications, liver adenoma, Hypertriglyceridemia, Lactic acidemia, nephropathy.

\section{Introduction}

Glycogen storage disease type I (GSDI) is an autosomal recessive disorder of glycogen metabolism that affects 1 in 100,000 live births.[1] The disorder is caused by mutations in genes G6PC and SLC37A4 that encode for glucose-6-phosphatase [type Ia] [2] and glucose-6-phosphate translocase [3][type Ib], represented in $80 \%$ of the patients by GSDIa and in $20 \%$ by GSDIb.[4,5] Glucose 6 phosphatase is responsible for the hydrolysis of G6P into glucose 1 phosphate and inorganic phosphate. Glucose-6phosphate (G6P) translocase transports glucose 6 phosphate into endoplasmic reticulum.[6] Glucose 6 phosphatase complex plays a central role in glycogenolysis and gluconeogenesis. Its defect produces hypoglycemia with short fasting, lactic acidemia, metabolic acidosis, hyperuricemia and hyperlipidemia. Its deficiency in the liver, kidney and intestine results in excessive glycogen storage in these organs.[1] GSDIb patients suffer from neutropenia with neutrophil dysfunction and inflammatory bowel disease (IBD).[7] Clinical features include hepatomegaly, truncal obesity, a rounded doll-like face, wasted muscles and growth retardation.[1]

Diagnosis is based on clinical features, biochemical parameters and enzyme activity in liver tissue.[8] Identification of genes mutations is categorical.[9,10]

\footnotetext{
${ }^{1}$ Hospital de Pediatría Juan P. Garrahan, Department of Inborn Errors of metabolism, Combate de los Pozos 1881 (C 1245 AAM), Buenos Aires, Argentina

${ }^{2}$ Hospital de Pediatría Prof Dr Juan P Garrahan, Genetics Deparment, Molecular Biology Laboratory, Buenos Aires, Argentina.
}

Received November 30, 2020, and in revised form March 4, 2021. Accepted for publication March 29, 2021.

Corresponding Author:

Veronica Bindi, Email: verogbindi@gmail.com 
Early diagnosis and treatment, with frequent meals, lactose and fructose restriction, uncooked cornstarch and/or gastric drip feeding avoids hypoglycemia, ensures optimal growth and allows patients to reach adulthood and to have a good quality of life.[11]

Treatment is monitored by anthropometric, biochemical parameters and imaging studies.[8] Adequate metabolic control decreases risk of acute metabolic derangements and long-term complications such as short stature, osteoporosis, pancreatitis, adenomas, hepatocellular carcinoma and renal disease.[12,13]

Renal disease can manifest as not only proximal and distal renal tubular dysfunction but also progressive glomerular injury that can result in functional renal impairment and even end-stage renal disease.

\section{Aim}

Description of clinical, molecular and biochemical data, diagnosis and long-term treatment of 36 patients with GSD I in a Metabolic Center of a High complexity Hospital in Argentina.

\section{Methods}

Data were retrospectively collected from medical records of 36 patients admitted in the hospital from January 1989 to December 2019. Follow-up was up to 18 years of age, then they were transferred to adult centers.

Diagnosis of GSD I was suspected based on clinical and biochemical data consisting in hypoglycemia, lactic acidemia, hypertriglyceridemia, hepatomegaly, failure to thrive, characteristic facies and normal creatinine kinase levels in blood.[1,13]

Diagnosis was confirmed with further functional tests such as glucagon and loading fructose test and/or molecular analysis.[14,15] The distinction between Ia and Ib until molecular diagnosis, was based on the presence of neutropenia defined as a neutrophil count $<500$ cells / $\mathrm{mm} 3$ in three consecutive complete blood counts and eventually intestinal inflammatory signs confirmed by gastrointestinal colonoscopies with tissue biopsy and elevated inflammatory biomarkers.[7]

Molecular analysis was performed on 21 patients, 16 with suspicion of GSD Ia and 5 with suspicion of GSD Ib. Samples from 9 patients underwent PCR (polymerase chain reaction) amplification of G6PC or SLC37A4 gene, followed by SSCP (single strand conformational polymorphism) and Sanger sequencing (Duke University in the Department of Molecular Genetics in 2003) and the remaining 12 underwent NGS (next generation sequencing) of exon and intron flanking sequences of both genes as part of a GSD gene panel. Variants were described in relation to the following reference sequences: NM_000151.4 (G6PC) and NM_001164277.1 (SLC37A4). Variants were classified according to the American College of Medical Genetics and Genomics (ACMG) guidelines for interpretation of sequence variants.[16]
Variables such as: age at first symptom, age at diagnosis and place of birth were analyzed using Mann Whitney test. Reasons for admission and consult type (referral from another institution or spontaneous consultations) were also collected.

Biochemical parameters analyzed included: triglycerides, cholesterol, uric acid, hemoglobin, lactic acid, creatinine kinase levels and neutrophil count before ingestion at baseline and during follow-up. They were compared using related-samples Friedman's tests. Data from abdominal ultrasounds and CT scans were collected at baseline and during follow-up.

Weight, height, head circumference, body mass index (BMI) and their respective standard deviations (SDS) for age were compared with the child growth charts of the World Health Organization (WHO).[17] Short stature was defined as height for age more than two standard deviations below the reference. Pre and post treatment values were analyzed by paired-sample Student's t-test. Diagnosis delay was compared among patients with or without microcephaly by Mann Whitney test.

Criteria for adequate metabolic control were based on European GSD I study (ESGSD I) and current GSD management guidelines.[18,13]

Anthropometric and biochemical parameters and medical evaluations were routinely performed every 6 months or annually depending on individual cases.

Number of admissions due to metabolic derangement (considered as a measure of poor outcome) was related to last height and last BMI SDS. Number of hospitalizations in Ia and Ib were analyzed by Pearson's correlation.

To determine whether or not patients were adherent to treatment[19], the following were taken into account: lack of attendance to medical appointments for more than one year and an annual hospitalization due to metabolic derangement due to omission of treatment referred by caregivers.

As disease complications, steatosis, adenomas or suggestive images of hepatocellular carcinoma and renal involvement such as tubulopathy, nephrolithiasis and/or glomerulopathy were evaluated through abdominal ultrasound and quantification of albumin or protein excretion in urine.[20,21] Patients were only considered to have microalbuminuria (MA) or proteinuria if two or more consecutive collections were abnormal. Citraturia and calciuria analysis were performed.

Time to adenoma formation and development of nephropathy were analyzed in a Kaplan-Meier survival curve. Patients were censored at the time of their latest negative imaging study or urine without proteinuria. An event was recorded if a patient had ultrasonography imaging demonstrating hepatic adenoma after previously negative imaging or the appearance of proteinuria or MA. Patients were stratified according to their triglyceride serum concentration during three years prior to the event or the last follow-up record and differences were analyzed with Log rank test.

Systemic arterial hypertension was considered when the 95th percentile value for age was higher. 
Statistical analysis was performed with IMB SPSS Statistics Software v20. A $p$-value $<0.05$ was considered statistically significant.

\section{Results}

Thirty-six patients were included in the study: 29 with GSD Ia and 7 with GSD Ib. Patients came from 33 families, where 6 were siblings. Eighteen were women and 18 men. Seventeen cases were born outside the country, 3 abroad (Uruguay) and the rest were from Buenos Aires. Six patients had a history of affected or deceased siblings (Table 1).

\section{Initial clinical data for GSD patients}

Initial clinical manifestations, age of first symptoms, age at diagnosis, and genotype are detailed in Table 1 . Referral reasons before arriving at definitive diagnosis are detailed in Figure 1. First signs and symptoms are detailed in Figure 2. All patients presented with more than one symptom, the most frequent was hepatomegaly with hypoglycemia (80\%). Three patients' diagnosis were suspected on family history.

Data as seizures, hypoglycemia and/or metabolic acidosis during neonatal period were recorded in 8 cases (Ia). Only two were diagnosed in this period because they had affected siblings.

Median age at diagnosis was 8 months (2 months to 11 years). Median age at first symptoms was 5 months (2 days to 2.5 years). Median delay in diagnosis was 3 months (15 days to 10 years). Ninety percent presented the first symptoms before one year of life and $50 \%$ were diagnosed before 8 months of age.

Median age of diagnosis in GSDIa was 9 months (1 month to 11 years) and median age of symptoms was 5 months (2 days to 2.5 years). Median diagnosis delay was 3 months (1 month to 10 years).

In GSD Ib, the median age of diagnosis was 7 months (2 months to 27 months) and median age at first symptoms were 4 months (50 days to 7 months). Median diagnosis delay was 3 months (10 days to 15 months).

Stratifying patients according to their geographical origin, 16 cases from Buenos Aires (less than $400 \mathrm{~km}$ from our Center) had a median age of onset of symptoms and diagnosis of 6 months ( 2 days to 2.5 years) and 10.5 months ( 1 month to 11 years), respectively. In 20 patients from the rest of the country and cases from abroad the median age of onset of symptoms and diagnosis were 4 months (2 days to 1 year) and 6.5 months (1 month to 2.7 years) respectively. The difference between these groups was not statistically significant.

Patients were referred for tertiary care in $48 \%$ of cases, $44 \%$ without the outside hospital referral and $8 \%$ request for a second medical opinion.

Diagnosis was confirmed by molecular analysis in 20 cases. Before 2002, diagnosis was confirmed by glucagon tests with 3-6 hours of fasting and loading fructose test in 16 cases.

\section{Dietary treatment}

Once diagnosis was confirmed, all patients received a normoprotein, normocaloric diet, with fructose and lactose restriction. They were also indicated uncooked cornstarch $1-2 \mathrm{~g} /$ $\mathrm{kg} /$ dose according to the interval needed to avoid hypoglycemia. When amylase was insufficient for adequate starch digestion (first 6 months) glucose polymers were used instead.

If patients did not tolerate 2 hours of fasting without hypoglycemia, continuous nocturnal gastric drip-feeding was indicated, with a glucose flow equivalent to the hepatic production according to age $(8-4 \mathrm{mg} / \mathrm{kg} /$ minute) administering an extra meal one hour before gastric drip-feeding suspension, to avoid hypoglycemia. Ascorbic acid, other vitamins and calcium supplements (lactose and fructose free) were indicated according to age requirements.

\section{Dietary treatment: GSD la patients}

Four children received maltodextrin until the age of 3, 6 and 8 months (until uncooked cornstarch was tolerated without gastrointestinal complaints and without hypoglycemia). Median age of starting cornstarch was 8 months (3 months to 6 years).

During the day, 6 patients required continuous gastric dripfeeding (CGDF) of a lactose-free formula with the addition of maltodextrin that provided a continuous glucose flow of 5.5 to 8 $\mathrm{mg} / \mathrm{k} /$ minute according to biochemical profile until a median age of 5 months ( 3 to 12 months). The starch doses ranged between $0.5-2 \mathrm{~g} / \mathrm{k} /$ dose with a mean of $1 \mathrm{~g} / \mathrm{k} /$ dose every 2 to 6 hours. Overnight, 12 patients received lactose-free CGDF for mean of 22 months, with the exception of one patient (case 3), which received CGDF for 13 years.

\section{Dietary treatment: GSD Ib patients}

Median onset of uncooked cornstarch was 9 months (6 to 24 months). The starch doses vary between $0.7-1.5 \mathrm{gr} / \mathrm{k} / \mathrm{dose}$ with a mean of $1.2 \mathrm{gr} / \mathrm{k} /$ dose. All patients required CGDF due to gastrointestinal complaints (frequent colic and / or diarrhea) and to maintain adequate metabolic control. During daytime, 3 patients received continuous CGDF until 6-24 months of age. One patient received CGDF until liver transplantation (10 years). Overnight, 6 patients received CGDF for a maximum period of 14 years (case 28) and a minimum of 18 months. 3 patients received CGDF until the age of 7, 9 and 10, then they underwent liver transplantation. Initial and long-term dietary indications were evaluated gradually: 6 of GSD Ib patients received continuous CGDF of a lactose-free formula for 12 to 24 hours during the first year. Three continued to receive CGDF for 10-12 hours. 


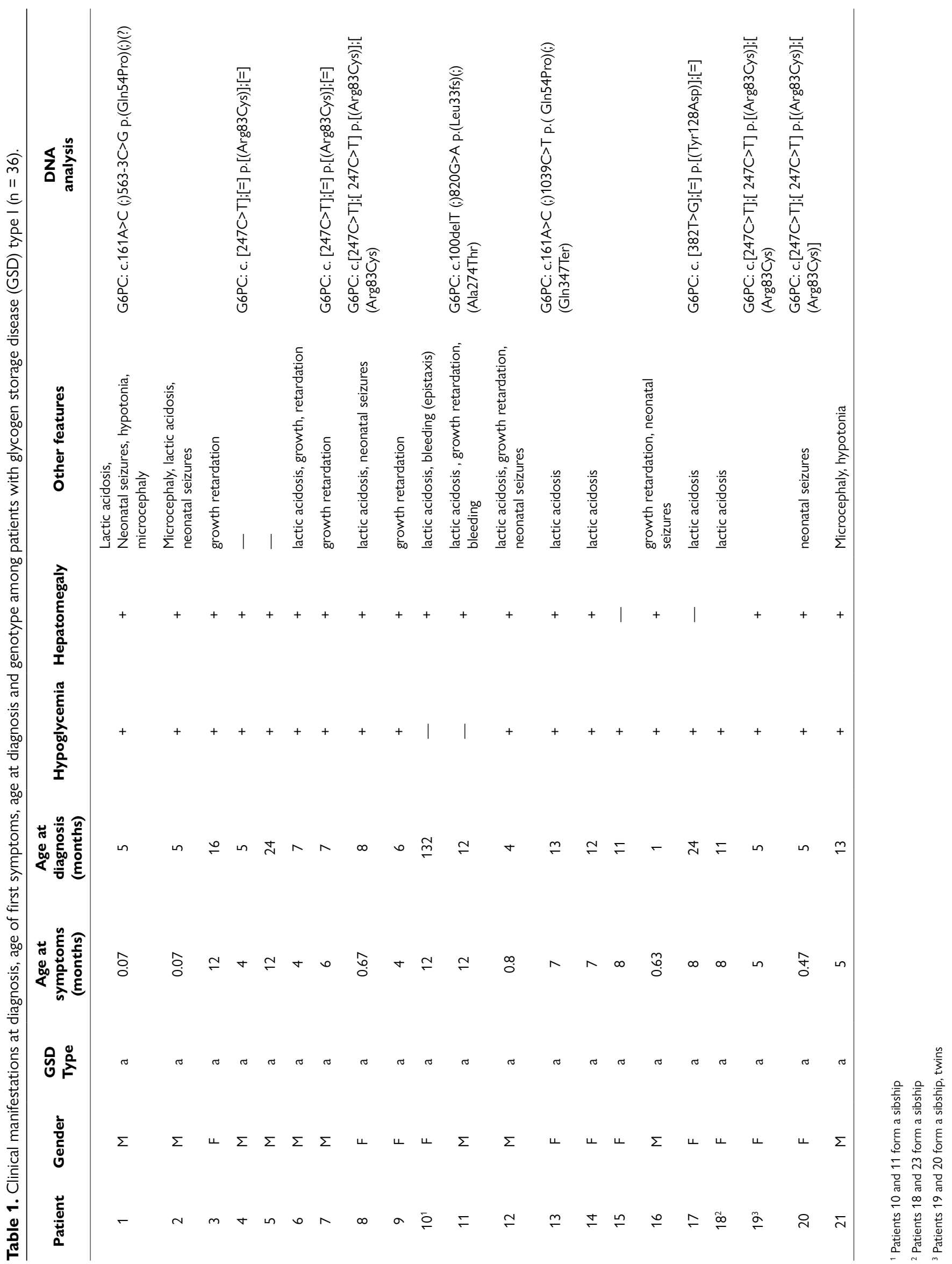




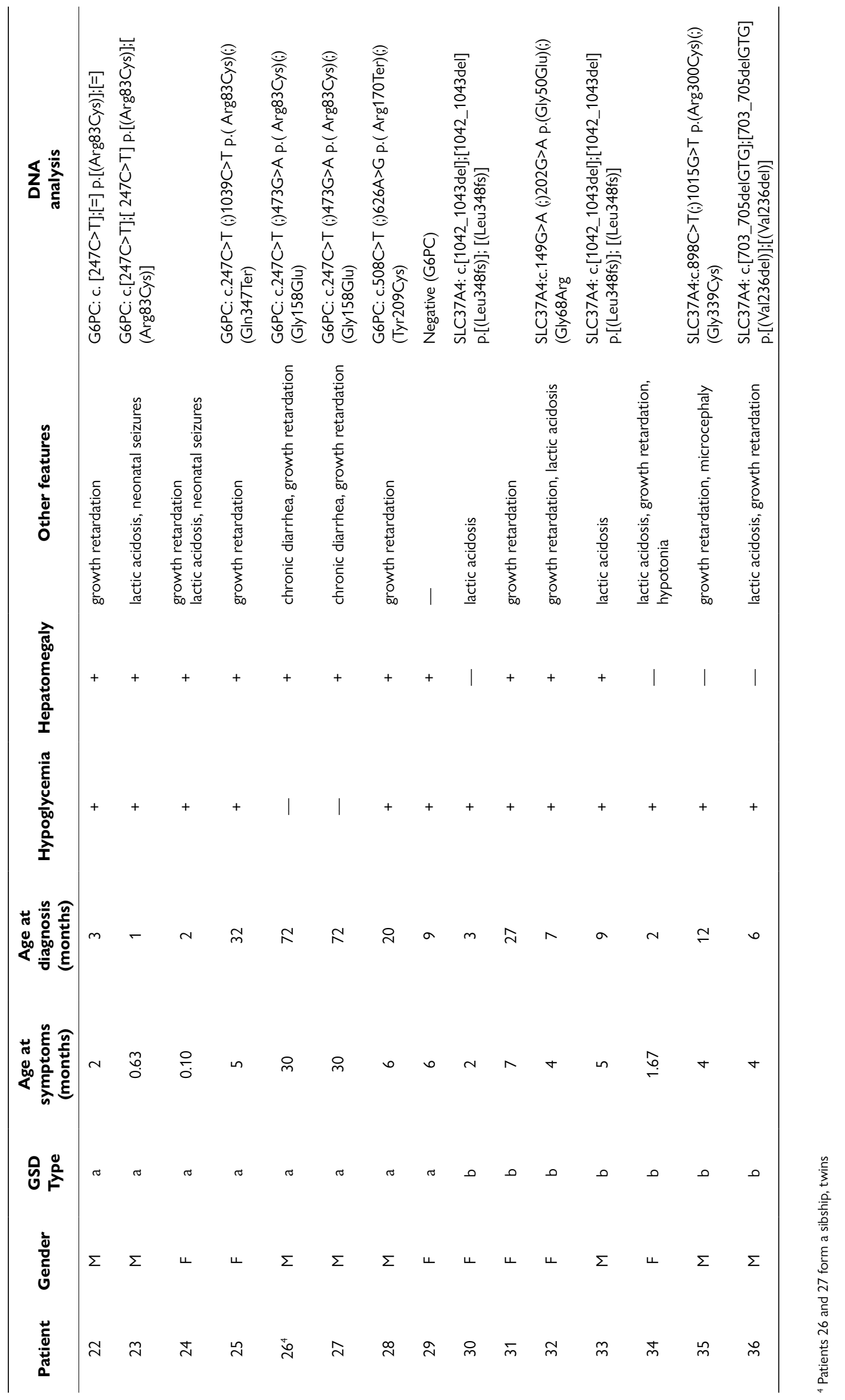



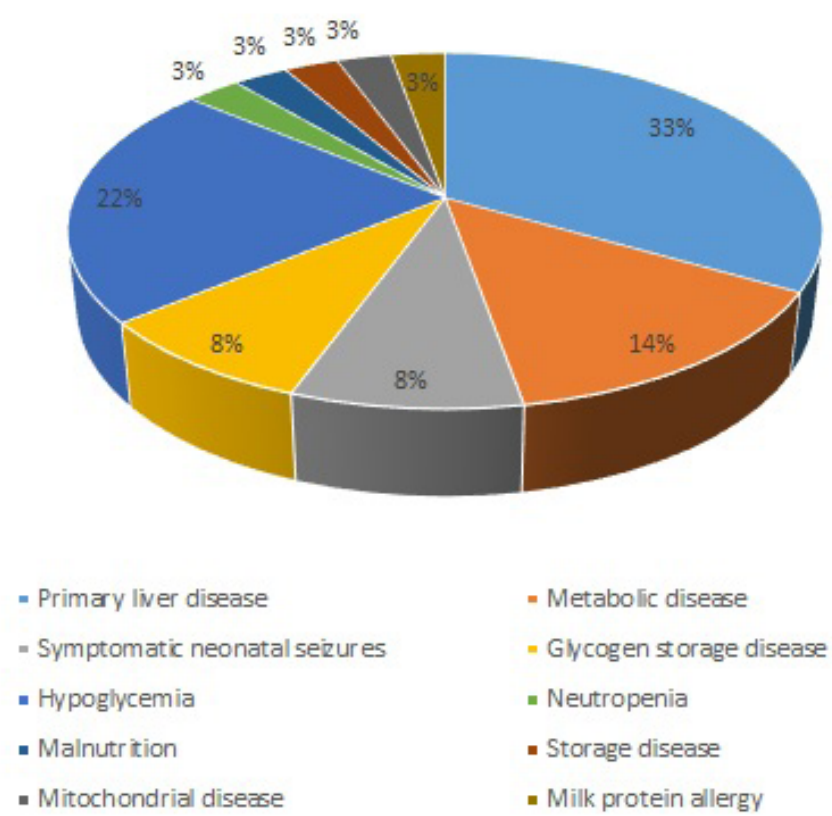

- Metabolic disease

- Glycogen storage disease

- Neutropenia

- Storage disease

- Milk protein allergy

Figure 1. Referral diagnoses

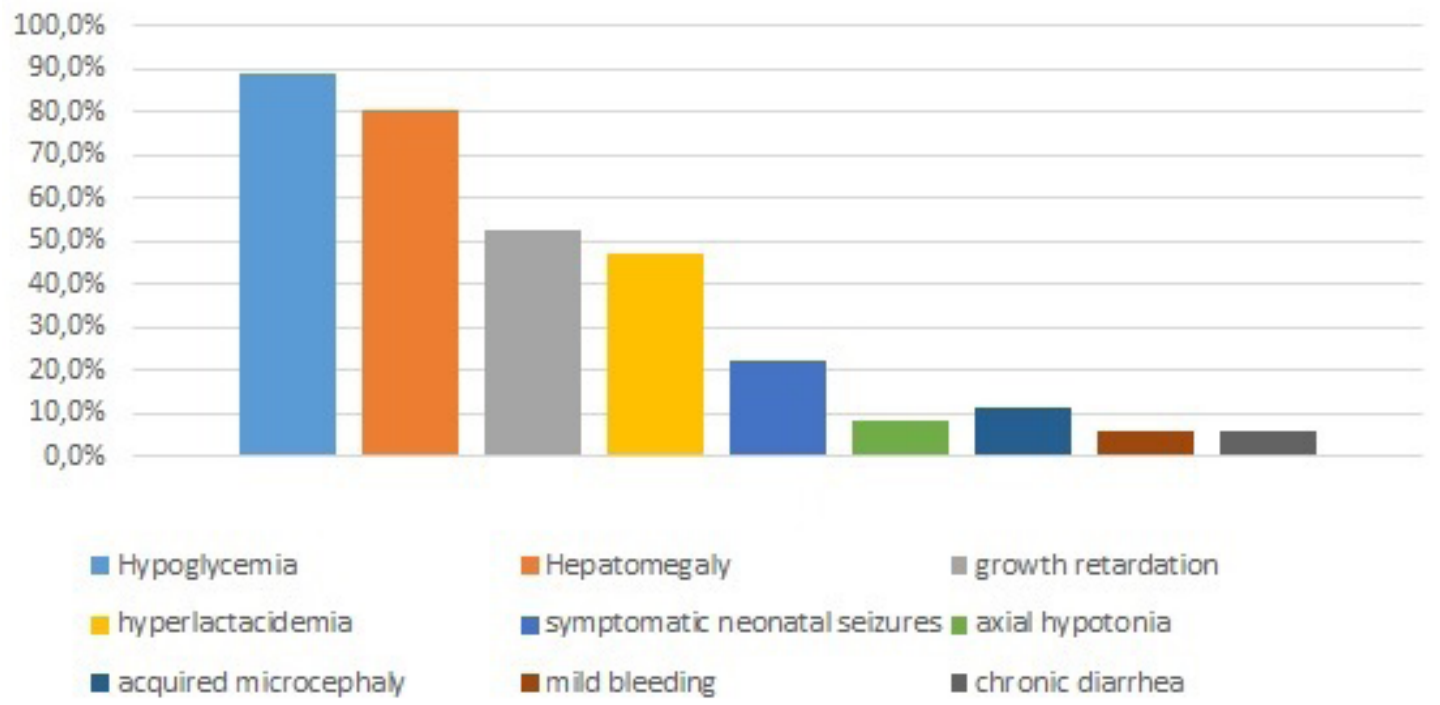

Figure 2. Initial clinical features: signs and symptoms.

\section{Use of supplements}

Eighty percent of the patients received ascorbic acid, 65\% received multivitamin complexes, $27 \%$ received iron supplements and $14 \%$ folic acid. Nighteen percent received allopurinol for hyperuricemia.

\section{Long-term follow-up}

Median age of follow-up was 9 years ( 9 months to 19 years). Overall survival was $91.6 \%$ (Table 2). Three patients were followed less than twelve months and were excluded for the "long-term follow-up" assessment. One of them died and the other two were followed in another center.

\section{Biochemical analysis}

Triglycerides, cholesterol, uric acid, lactate and hemoglobin values before treatment were available in 35 patients. These values were analyzed before and after treatment.

Median triglycerides before treatment was $457.5 \mathrm{mg} / \mathrm{dL}$ (109$1189 \mathrm{mg} / \mathrm{dL})$, at 4 years of follow-up it was $247 \mathrm{mg} / \mathrm{dL}$ (71-1055 
Table 2. Clinical features during follow-up and last anthropometric assessment of GSD I

\begin{tabular}{|c|c|c|c|c|c|c|c|c|c|c|}
\hline Patient & $\begin{array}{l}\text { GSD } \\
\text { type }\end{array}$ & $\begin{array}{c}\text { Last } \\
\text { height } \\
\text { (SDS) }\end{array}$ & $\begin{array}{l}\text { Last } \\
\text { BMI } \\
\text { (SDS) }\end{array}$ & $\begin{array}{c}\text { Liver } \\
\text { adenomas } \\
\text { (LA) }\end{array}$ & $\begin{array}{c}\text { Age of } \\
\text { detection } \\
\text { LA (years)/ } \\
\text { evolution }\end{array}$ & $\begin{array}{c}\text { Nephropathy } \\
\text { (N) }\end{array}$ & $\begin{array}{c}\text { Age of } \\
\text { detection } \mathbf{N} \\
\text { (years)/type }\end{array}$ & $\begin{array}{c}\text { Liver } \\
\text { transplant/ } \\
\text { age (years) }\end{array}$ & $\begin{array}{c}\text { Age at death } \\
\text { (years)/Cause } \\
\text { of death }\end{array}$ & $\begin{array}{c}\text { Follow } \\
\text { up } \\
\text { (years) }\end{array}$ \\
\hline 2 & $\mathrm{a}$ & 0.65 & 1.8 & no & & no & & & & 14 \\
\hline 3 & a & -1.94 & 2.3 & yes & $\begin{array}{c}\text { 11.6/suspected } \\
\text { HCC }\end{array}$ & yes & $16 / \mathrm{MA}$ & 13.6 & & 17 \\
\hline 5 & $\mathrm{a}$ & 0.1 & $N / A$ & no & & no & & & $\begin{array}{l}\text { 20/metabolic } \\
\text { derangement }\end{array}$ & 12 \\
\hline 6 & a & -3 & $N / A$ & no & & no & & & & 7 \\
\hline 7 & $\mathrm{a}$ & -0.92 & 1.7 & no & & no & & & & 16 \\
\hline 8 & $\mathrm{a}$ & -1.5 & $N / A$ & no & & no & & & & 19 \\
\hline 12 & a & -2.1 & -2.1 & no & & no & & & $\begin{array}{c}0.92 / \text { metabolic } \\
\text { derangement }\end{array}$ & 1 \\
\hline 13 & a & -0.58 & $>3$ & no & & no & & & & 0.9 \\
\hline 14 & a & -1.27 & 1.3 & no & & yes & 10.3/MA & & & 11 \\
\hline 15 & $\mathrm{a}$ & -1 & 0.8 & no & & no & & & & 7 \\
\hline 16 & a & -1.5 & 2.3 & no & & yes & 7.6/MA & & & 10 \\
\hline 17 & $\mathrm{a}$ & -0.5 & $N / A$ & no & & no & & & & 8 \\
\hline 18 & $\mathrm{a}$ & 0.27 & $N / A$ & no & & no & & & $\begin{array}{l}\text { 4/respiratory } \\
\text { insufficiency }\end{array}$ & 0.8 \\
\hline 25 & $\mathrm{a}$ & -2 & 1.7 & no & & yes & $4 / M A$ & & & 2 \\
\hline 26 & $\mathrm{a}$ & -1.77 & -1 & no & & $N / A$ & & & & 4 \\
\hline 27 & a & -1.64 & -1.1 & no & & $\mathrm{N} / \mathrm{A}$ & & & & 4 \\
\hline 28 & $b$ & -1.45 & 1 & no & & $N / A$ & & & & 1 \\
\hline 29 & $b$ & -0.92 & 0.4 & no & & no & & & & 19 \\
\hline 30 & $b$ & -1.38 & 1.2 & no & & no & & & & 14 \\
\hline 31 & b & -2 & $N / A$ & Yes & $\begin{array}{l}\text { 10/disappeared } \\
\text { after } 2 \text { years }\end{array}$ & yes & $14.8 /$ proteinuria & & & 12 \\
\hline 32 & $b$ & -1.4 & 1 & no & & no & & $\begin{array}{c}7.6 \\
\text { intractable } \\
\text { hypoglycemias }\end{array}$ & & 18 \\
\hline 33 & $\mathrm{~b}$ & -0.44 & 1.8 & yes & $\begin{array}{c}\text { 2.7/suspected } \\
\text { HCC }\end{array}$ & yes, & $\begin{array}{l}\text { 11.1/MA } \\
\text { progressed } \\
\text { proteinuria }\end{array}$ & 9.6 & & 12 \\
\hline 34 & $b$ & -2.66 & 0.9 & yes & $\begin{array}{c}\text { 5.8/suspected } \\
\text { HCC }\end{array}$ & yes & 5.1/proteinuria & 10.6, HCC & & 18 \\
\hline 35 & b & -2.91 & 1.8 & no & & yes & 5.8/MA & & & 6 \\
\hline 36 & $b$ & -3.1 & -0.8 & no & & no & & & & 1.5 \\
\hline
\end{tabular}

N/A: not available

MA: microalbuminuria 
$\mathrm{mg} / \mathrm{dL})$ and at 7 years $272.5 \mathrm{mg} / \mathrm{dL}(67-1767 \mathrm{mg} / \mathrm{dL})(p=0.003)$. After 6 years of follow-up, a greater dispersion of triglycerides values was observed. In this period, $40 \%$ of the patients were over 10 years of age (Figure S1).

The median lactic acid level before treatment was $57.2 \mathrm{mg} /$ $\mathrm{dL}(19.7-142 \mathrm{mg} / \mathrm{dL})$, at 4 years $29.7 \mathrm{mg} / \mathrm{dL}(8.9-64.6 \mathrm{mg} / \mathrm{dL})$ and at 7 years $32.4 \mathrm{mg} / \mathrm{dL}(13.6-63.3 \mathrm{mg} / \mathrm{dL})(p<0.001)$ (Figure S2).

There were no significant changes in cholesterol, hemoglobin and uric acid values before and after treatment.

Only $15 \%$ of our patients reached parameters for good metabolic control. One of them presented complications (case 33). Sixty-four percent reached two of the parameters (uric acid and triglycerides). Instead, $85 \%$ had triglycerides values $<500 \mathrm{mg} / \mathrm{dL}$.

\section{Specific complications in patients with glycogen storage disease type lb}

Persistent neutropenia was first noted between the ages of 2 months and 6 years. Inflammatory bowel disease was first documented with a median age of 6 months ( 2 months to 120 months). A bone marrow biopsy was performed prior to the administration of granulocyte colony-stimulating factor (G-CSF). Doses of C-CSF varied according to neutrophil values, between $5-10 \mathrm{mcg} / \mathrm{kg} / \mathrm{day}$ subcutaneously every $24-72$ hours.

Diarrhea was reported in all GSD Ib patients. Gastrointestinal endoscopy was carried out in 5 cases. 5 -aminosalicylic acid was administered in cases 30 and 32 from 5 years of age at a dose of $30-40 \mathrm{mg} / \mathrm{kg} / \mathrm{day}$ with a variable response.

\section{Specific complications in patients with glycogen storage disease type la}

Diarrhea was reported in 3 of the GSD Ia patients. Two cases experienced chronic diarrhea. Gastrointestinal endoscopy was carried out at 11 years and 6 years. Histology showed ulcerative colitis with mild activity in the first case (case 6) and nonspecific colonic inflammation and biomarkers within normal ranges (case 26).

\section{Growth assessment: Weight, height and BMI SDS}

Height SDS pre-treatment and at last follow-up for each patient are summarized in Table 2.

Height at latest follow-up was below -2.0 SDS in $22.2 \%$ $(8 / 36)$. Four of them were Ib patients. BMI at last follow up (available for 29 patients) was upper +2 SDS at $24 \%$, all of them Ia (7/29).

Statistically significant increases in last height SDS ( $p=$ 0.012 ) were seen with treatment but not in last weight and BMI SDS (Figure 3). This increase was seen in GSD Ia patients (mean height before treatment -1.71) was significantly higher than after $(-1.03)(p=0.001)$ but not in GSD Ib patients (mean height before treatment -1.64, after treatment -1.89) $(p>0.05)$.

Stratifying patients according to their adherence, we observed that 22 patients with good adherence had increased height SDS after treatment that was statistically significant $(p=0.049)$, but we did not observe such changes in patients with low adherence to treatment.

\section{Admissions}

After starting dietary treatment, metabolic derangement that required admission was reported in $86 \%$ of the GSD Ia and in $100 \%$ of the GSD Ib patients. Median number of admissions/ year was 0.77 (0-3.4). Infections, especially combined with vomiting and/or diarrhea were the most common cause of acute metabolic derangement. In GSD Ib, $21 \%$ of admissions were because of infections. Admissions in Ib patients were more common than Ia $(p=0.002)$.

Mean height SDS was -1.11 ( -3 to 0.7 ), and median of admissions per year was 0.77 (0 to 3.4). Figure 4 provides a graphical representation of the significant correlation between height SDS and number of admissions per year ( $p 0.031$ ). Patients who presented more admissions had a lower height SDS.

\section{Liver adenomas}

Five patients had liver adenomas at a median age of 9 years (2.6 to 11.5 years). Serum levels of alpha-fetoprotein and carcinoembryonic antigen had remained within normal range. One patient developed carcinoma (Table 2). In two patients, a remission of adenoma(s) was observed after adjusting dietary therapy. Three of them underwent liver transplantation.

We analyzed age at diagnosis, height and BMI SDS, median triglycerides and compliance in the two groups (adenoma vs no adenoma) and found no significant differences. Patients in the "no adenoma"-group younger than 2.5 years old were excluded (Table S1).

When patients were stratified based on triglyceride fluctuations along time, it was evidenced that with sustained triglycerides values above $500 \mathrm{mg} / \mathrm{dL}$, liver adenomas appeared earlier than in those with values below $(p=0.009)$ (Figure 5).

\section{Renal disease}

Median age of onset of nephrolithiasis / nephrocalcinosis was 9.8 years ( 2 months to 20 years). Two of 5 cases showed hypocitraturia and were treated with potassium citrate. One of them presented hypercalcuria and was treated with calcitriol and calcium carbonate (case 34).

Elevated urine albumin excretion was detected in 8 of 36 GSD patients (22\%). Median age of onset of microalbuminuria (MA) or proteinuria was 9.5 years (3.6 to 16 years). Half were phenotype Ib. All patients showed normal creatinine and urea 


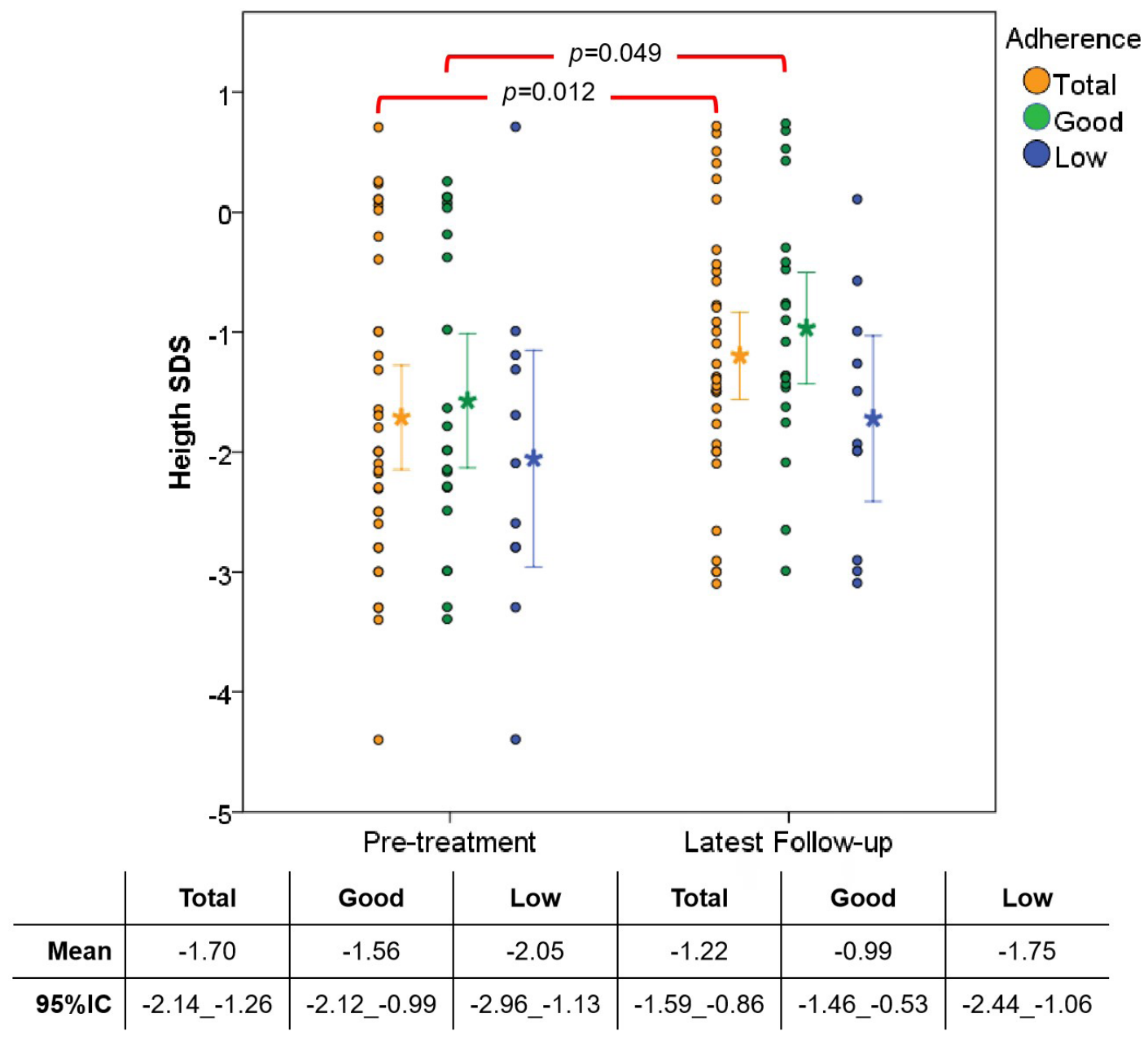

Figure 3. Height (SDS) pretreatment and at latest follow-up stratified according to their adherence. Patients `height are represented as dots individually on the graph. Means are represented as stars and $95 \% \mathrm{Cl}$ as bars and indicated below. Red braces indicate statistical significance.

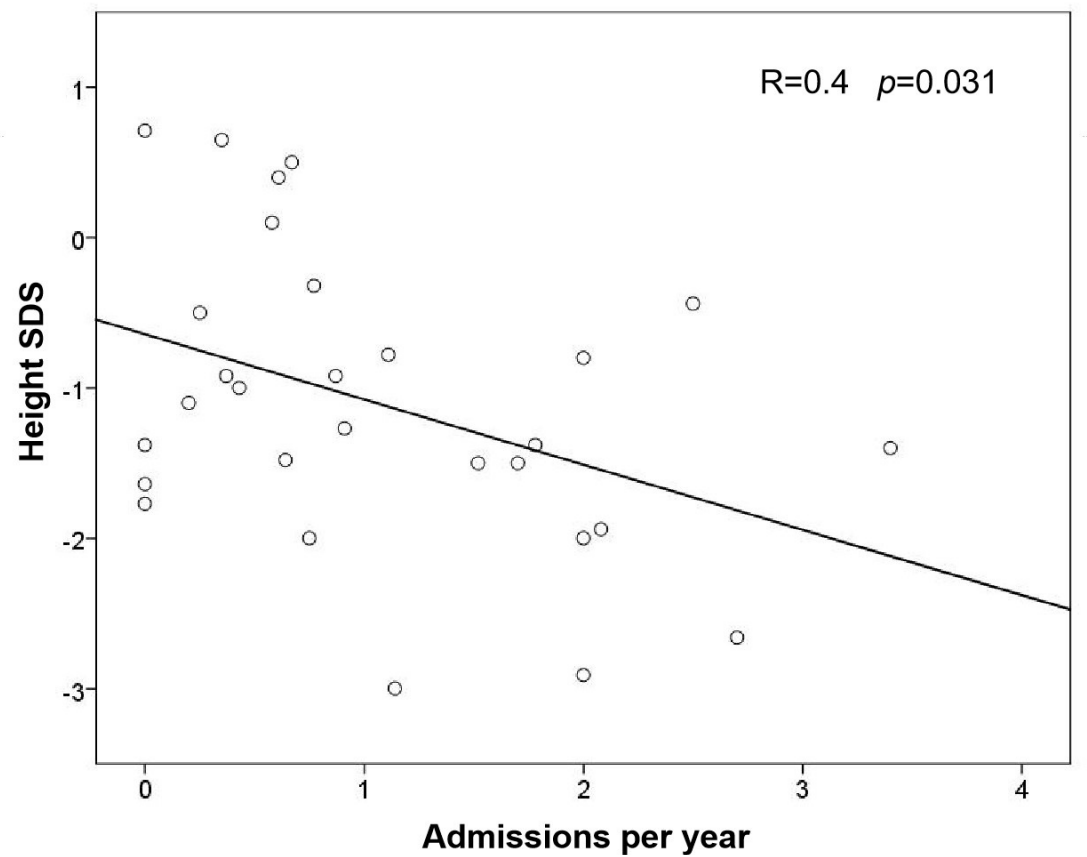

Figure 4. Correlation between last height SDS and number of admissions per year. 


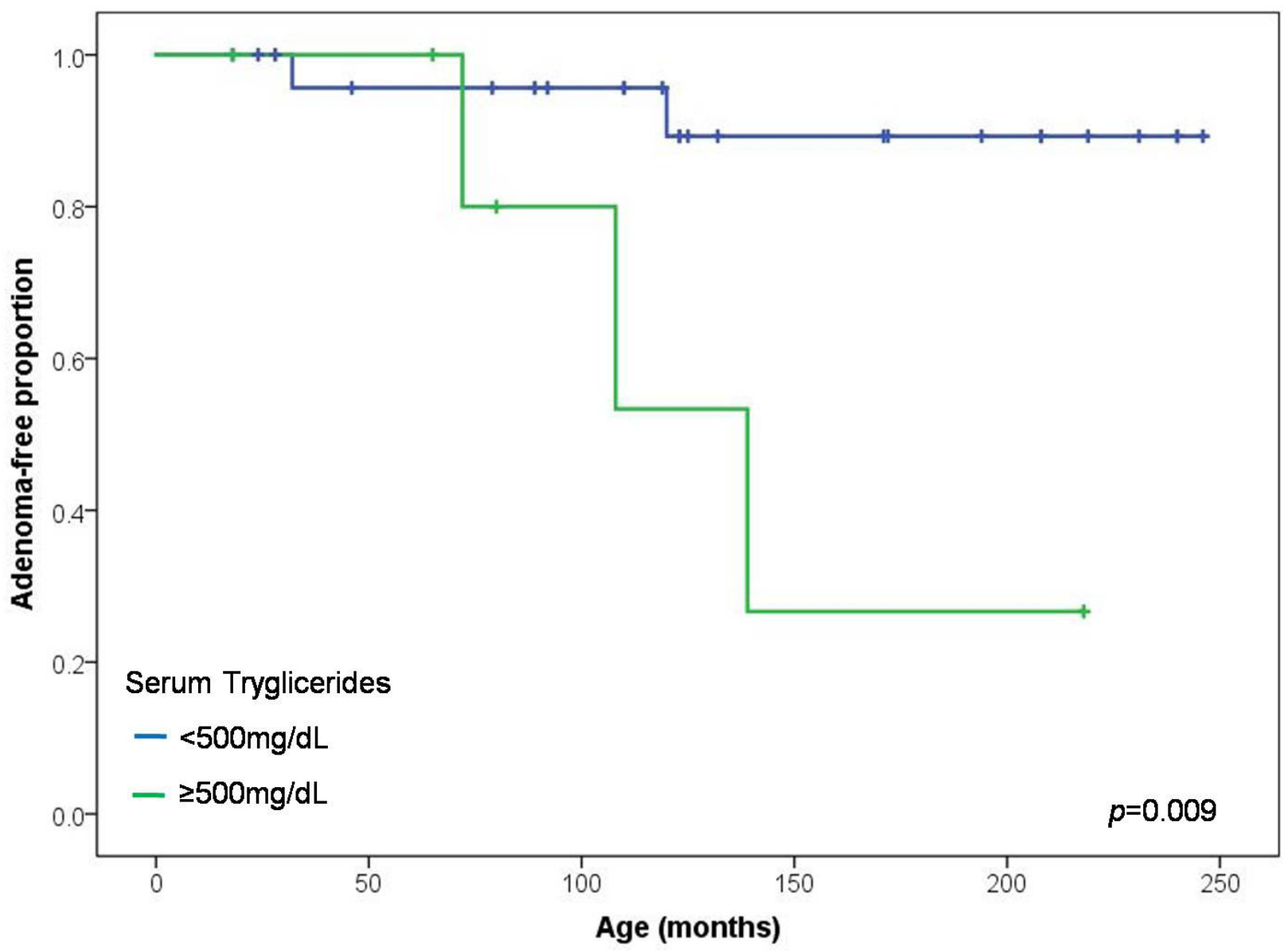

Figure 5. Kaplan-Meier survival curve of adenoma-free progression in GSD I based on three-year mean triglyceride concentration. $\mathrm{P}$ value between both groups is indicated.

concentrations in blood. Proteinuria was detected at a median age of 9.9 years (5.1 to 14.8) and MA at a median age of 7.6 years (4 to 16.2).

We analyzed age at diagnosis, height and BMI SDS, median triglycerides and compliance in the two groups (nephropathy vs no nephropathy) and found no significant differences (Table S2).

Angiotensin converting enzyme (ACE) inhibitor therapy was started after MA/proteinuria documentation at doses 0.12-0.2 $\mathrm{mg} / \mathrm{kg} /$ day. Kidneys ultrasound images from 2 patients exhibited markedly increased parenchymal echogenicity and absence of corticomedullary differentiation.

When patients were stratified according to triglyceride fluctuations, it was evidenced that with sustained triglycerides values above $500 \mathrm{mg} / \mathrm{dL}$, nephropathy appears earlier than in those with values below $(p=0.046)$ (Figure 6).

Hypertension, requiring treatment, was observed in $9 \%$ of GSD I (cases 3, 16 and 29). In case 3 hypertension was detected during liver transplantation. In case 16 it was associated with MA and case 29 suffered an acute kidney injury after acute metabolic derangement. All received amlodipine 0.12-0.13 $\mathrm{mg} / \mathrm{kg} /$ day.

\section{Neurological and cognitive profile}

All school-age patients received standard education. Two patients presented behavioral disorders that required curricular adaptations (cases 23 and 35), both had frequent hypoglycemia and one of them presented epilepsy. A patient has sensorineural deafness from birth.

$13.8 \%$ of patients received anti-epileptics drugs because epilepsy. In 4 cases, neuroimaging studies were available, affecting the parietal and occipital lobes and in one case was an increase in subarachnoid spaces.

Microcephaly was reported in 4 patients at diagnosis. The difference in diagnosis delay in cases with and without microcephaly was not statistically significant (6.6 months and in the remaining 3 months). 


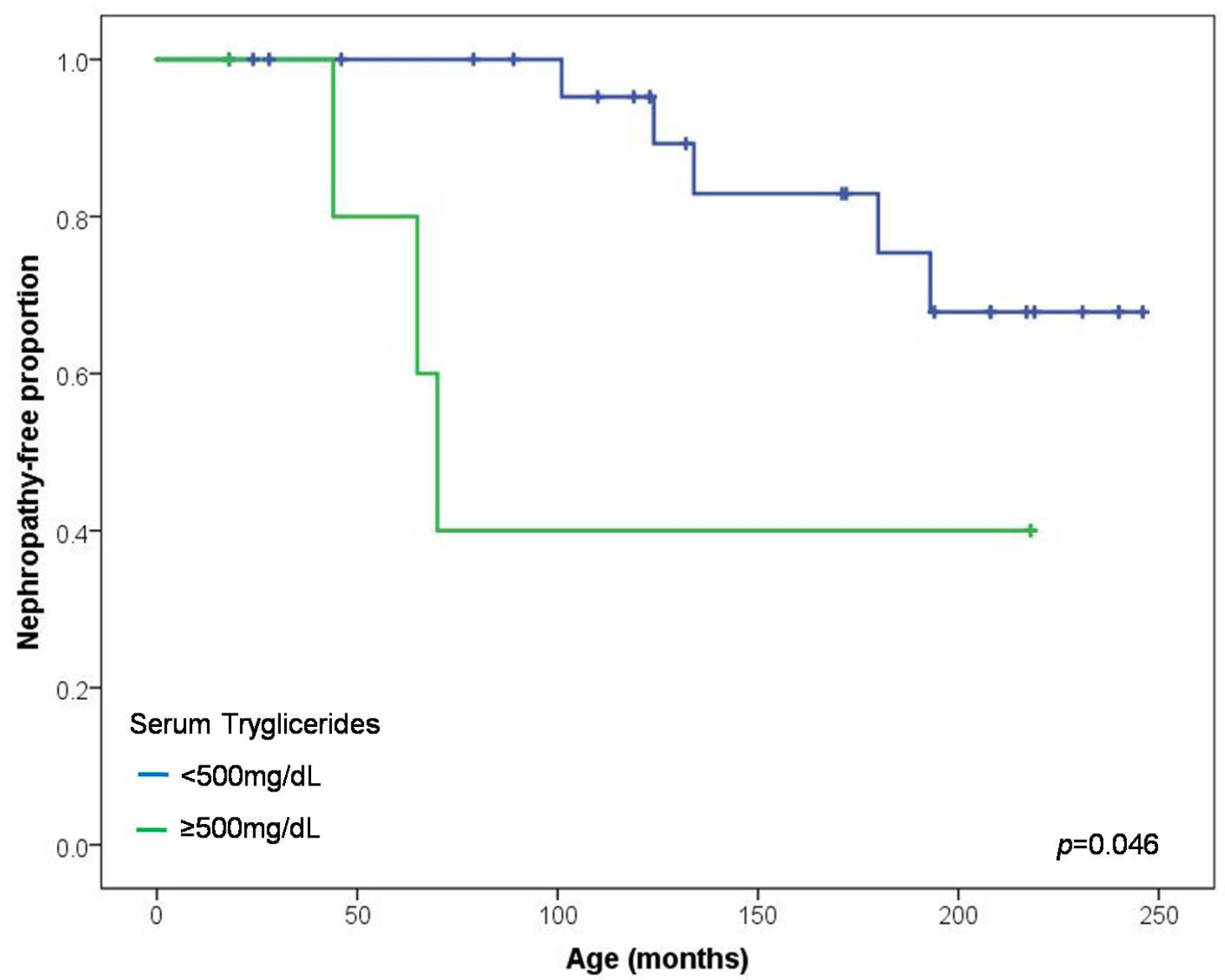

Figure 6. Kaplan-Meier survival curve of nephropathy-free progression in GSD I based on three-year mean triglyceride concentration. p value between both groups is indicated.

\section{Bleeding tendency}

Complications due to bleeding tendency were reported in 3 of the patients manifested as recurrent epistaxis and gastrointestinal tract bleeding. All of them were associated with poor metabolic control.

\section{Others:}

One patient presented a sensory-motor neuropathy with spastic paraplegia. In 2 cases bilateral cataracts were reported. Four pairs of siblings had hypothyroidism.

\section{Liver transplant GSD patients}

Three patients (cases 32, 33 and 34) with GSD Ib and 1 with GSD Ia (3) underwent liver transplant. Indications were liver adenomas and poor metabolic control. All GSD Ib had neutropenia and inflammatory bowel disease. One had kidney involvement (proteinuria) prior to transplantation (34). Mean age of transplantation was 9.7 years (7-13 years). All received a cadaveric liver transplant. Median time follow-up was 5.5 years (2-12).
Immunosuppressive regimen consisted of steroids, tacrolimus, sirolimus, mycophenolate and cyclosporine. Histology of liver explant revealed adenomas, steatosis, fibrosis and hepatocellular carcinoma (34).

Overall survival was $100 \%$. Biochemical parameters were normalized in all cases and in 3/4 growth delay recovered after transplantation.

MA was detected after liver transplantation in 2 cases. During transplantation procedure, patient 33 (Ib) suffered acute liver injury secondary to vena cava thrombosis and, as a consequence, acute kidney injury. Five months later MA was detected evolving to proteinuria at present. Patient 3 (Ia) had his first MA detected after two years and 5 months. They received nephrotoxic agents for immunosuppressive regimen: tacrolimus, sirolimus and deltisone.

Long-term complications were: obesity and MA in case Ia (3) and in GSD Ib MA (33) that evolved to proteinuria, nephrocalcinosis (34), thyroid carcinoma (34) and persistent neutropenia (3/3). Two persisted with splenomegaly and thrombocytopenia. 


\section{Molecular analysis}

Molecular analysis of G6PC gene detected both DNA variants in 11 of the 16 patients with suspicion or diagnosis of GSDIa, only one variant in 4 and resulted negative in one patient. Ten different variants were identified in the G6PC gene, among 22 of 28 unrelated alleles (79\%). The most frequent variant was p.Arg83Cys, observed in 11 alleles (39\%) followed by p.Gln54Pro and p.Gln347Ter, each one detected in 2 alleles (7\%). Five patients with suspicion or diagnosis of GSDIb underwent molecular analysis of SLC37A4 gene, which detected both variants in all of them, identifying 6 different variants. Two patients were homozygous for c.1042_1043delCT, accounting for 4 of the 10 alleles (40\%). Four variants were detected for the first time in this study: c.382T $>\mathrm{G}$ (p.Tyr128Asp), c.473G $>$ A (p.Gly158Glu) and c.820G >A (p.Ala274Thr) in the G6PC gene, and c.898C >T (p.Arg300Cys) in the SLC37A4 gene. Classification of each variant according to the ACMG guidelines is described in Table 3.

\section{Discussion}

GSD I (known since 1929) is one of inborn errors of metabolism easy to suspect and diagnose, since its signs are quite specific. $[5,22]$ Early treatment and close follow-up allow a good prognosis with adequate quality of life. However, its diagnosis is often delayed, and may even cause early death.

From the review of 36 cases seen in our center, median age at diagnosis was 8 months, regardless of where they came from. The first symptoms appeared before 6 months in more than $50 \%$ of the patients in this cohort. However, the diagnosis was delayed.
Most common initial signs were hypoglycemia and hepatomegaly. Hypoglycemia is a frequent symptom in healthy newborns in the first 48 hours of life, if it lasts longer, other causes should be investigated.[23] Diagnosis may go unnoticed if an intravenous glucose flow is given because blood glucose and lactic acid are normalized.[24] We suggest that whenever a newborn presents hypoglycemia, it should be controlled with a 5-hour fast before considering that it was a physiological hypoglycemia. This avoids overlooking patients with GSD. Because it is a recurring phenomenon, patients tolerate very low blood glucose values with few clinical signs. An early biochemical marker is lactic acid, which generally is associated with normal glucose levels.[25] Hyperlipidemia is also a clue for diagnosis. It improves with medical therapy.[26,27]

It can be hypothesized that GSDI patients, who present hypoglycemia and increased serum lactate levels, should be protected from the hypoglycemia-induced brain damage.[25] However, recurrent hypoglycemic episodes in infancy and childhood seem to play a key role in the pathogenesis of cerebral injury in GSDI.[28] Microcephaly and seizures can be long-term sequelae.

Another suggestive sign is hepatomegaly. It is usually soft and a detailed medical examination allows it not to be missed. "Doll-like face" is very characteristic and guiding.

The main differential diagnosis includes other forms of GSD associated with hepatomegaly and hypoglycemia, especially GSD type III and Fanconi Bickel syndrome but clinical findings and biochemical workup can differentiate it.

Other differential diagnoses include diseases that primarily affect the liver such as infectious, toxic or inflammatory hepatitis.

Table 3. Gene variants found in 21 patients with GSDI

\begin{tabular}{|c|c|c|c|c|c|c|}
\hline \multirow{2}{*}{ Gene } & \multicolumn{2}{|c|}{ Variant } & \multirow{2}{*}{ Location } & \multirow{2}{*}{$\begin{array}{c}\text { Number of } \\
\text { alleles* }\end{array}$} & \multirow{2}{*}{$\begin{array}{c}\text { Reported or } \\
\text { Novel }\end{array}$} & \multirow{2}{*}{ ACMG classification } \\
\hline & c.DNA & Protein & & & & \\
\hline \multirow{7}{*}{ G6PC } & c. $161 \mathrm{~A}>\mathrm{C}$ & p.Gln54Pro & Exon 1 & 2 & Reported & Likely pathogenic \\
\hline & c. $382 T>G$ & p.Tyr128Asp & Exon 3 & 1 & Novel & Likely pathogenic \\
\hline & c. $473 \mathrm{G}>\mathrm{A}$ & p.Gly158Glu & Exon 4 & 1 & Novel & Uncertain significance \\
\hline & c. $626 \mathrm{~A}>\mathrm{G}$ & p.Tyr209Cys & Exon 5 & 1 & Reported & Likely pathogenic \\
\hline & c. $820 \mathrm{G}>\mathrm{A}$ & p.Ala274Thr & Exon 5 & 1 & Novel & Likely pathogenic \\
\hline & c.1004delT & p.Leu335fs & Exon 5 & 1 & Reported & Pathogenic \\
\hline & c. $1039 \mathrm{C}>\mathrm{T}$ & p.Gln347Ter & Exon 5 & 2 & Reported & Pathogenic \\
\hline \multirow{3}{*}{ SLC37A4 } & $c .898 \mathrm{C}>\mathrm{T}$ & p.Arg300Cys & Exon 7 & 1 & Novel & Likely pathogenic \\
\hline & c. $1015 \mathrm{G}>\mathrm{T}$ & p.Gly339Cys & Exon 10 & 1 & Reported & Pathogenic \\
\hline & c.1042_1043del & p.Leu348fs & Exon 10 & 4 & Reported & Pathogenic \\
\hline
\end{tabular}

*unrelated alleles 
Serum concentration of transaminase are increased in these disorders, but in GSD I often return to normal or near-normal levels with appropriate treatment.

Because of severe hepatomegaly, lysosomal storage disorders such as Gaucher disease and Niemann Pick type B disease may initially be confused with GSD I. However, there is striking splenomegaly in lysosomal storage disorders and hypoglycemia does not occur.

The conjunction of hypoglycemia, liver involvement and lactic acidemia can lead to the misdiagnosis of mitochondrial disease.

If the patient initially presents with hypoglycemia without hepatomegaly, the differential diagnosis for hypoglycemia will also include GSD 0, fatty acid oxidation disorders, defects of gluconeogenesis such as fructose-1, 6-bisphosphatase deficiency, disorders of carbohydrate metabolism such as hereditary fructose intolerance, and endocrinopathies such as congenital hyperinsulinism, adrenal insufficiency or growth hormone deficiency. Clinical findings and biochemical workup can differentiate them.

Failure to thrive and chronic diarrhea can lead to the misdiagnosis of milk protein allergy, as we could see in one patient.

Before molecular analysis, diagnosis through enzyme activity in liver tissue was not available in our center. Abnormal functional tests (glucagon and fructose) and family history were helpful.[14] These two pathological functional tests are characteristic of GSD I. However, we must keep in mind that glucagon stimulation test may lead to worsen metabolic acidosis in GSD I and therefore is not recommended to make the diagnosis of GSD I. If it is performed, very close monitoring is required due to the risk of acute acidosis. Nowadays, noninvasive molecular genetic testing through full gene sequencing of the G6PC (GSD Ia) and SLC37A4 (GSD Ib) genes can be used for confirming the diagnosis.

Histopathological analysis of hepatic biopsy is not recommended for diagnosis because findings are nonspecific (glycogen and fat in the cytoplasm).[29] Diagnosis was suspected in all cases by family history or by clinical signs and biochemical parameters. Molecular diagnosis finding pathogenic variants in G6PC/SLC37A4 genes is categorical.[30]

The most frequent pathogenic variant found in this work was p.Arg83Cys, present in 39\% of alleles in GSD Ia patients, followed by p.Gln347Ter and p.Gln54Pro. P.Arg83Cys is one of the most frequent variants found around the world among GSD Ia patients. All of them have been identified in Caucasian GSD Ia patients[31 ${ }^{1}$, as well as in patients from Argentina[32] and other Latin American populations.[33] Among patients with GSD Ib, p.Leu348fs was the most frequent variant, accounting for $40 \%$ of the alleles, as in white patients[22] and patients from a Brazilian cohort.[33]

NGS technology seems to have a better sensitivity, compared to the SSCP followed by PCR and Sanger sequencing algorithm, since both variants were detected in all the patients studied by NGS, whereas with the former algorithm in 5 patients their genotype remained incomplete after the analysis. The advent of NGS for the precise diagnosis of GSD made possible to avoid invasive tests and delays, as well as the evaluation of patients with atypical forms of the disease.[34]

Treatment consists of maintaining normal blood glucose levels, avoiding gluconeogenesis and acidosis. For this, it is necessary to administer glucose equivalent to hepatic production. [35] The first advance in treatment was to implement a nocturnal gastric drip feeding; later, administration of uncooked cornstarch. [36] This last resort may be limited in the first months of life, due to insufficient amylase production and insufficient starch digestion. Therefore, some patients require glucose polymers or gastric drip feeding until the starch is properly digested.

There is no clear definition of "good metabolic control" for GSD I, although several endpoints including growth and laboratory parameters such levels of lactate, triglycerides, cholesterol and uric acid are mentioned in the GSD I management guidelines. $[18,13]$ Uric acid is an unreliable marker in the setting of allopurinol treatment. Because lactate values fluctuate rapidly throughout the day in response to diet and treatment, many studies do not take it into account as a metabolic control parameter. However, in our cohort lactate decreased after treatment significantly. Collected values were those according to hours of fasting tolerated and without metabolic decompensations. This avoids fluctuations.

Triglyceride levels are considered the most useful parameter for chronic metabolic control.[18,26] In our cohort, triglycerides have changed significantly with treatment in the first years after which they began to rise. This may be related to suboptimal metabolic control during this age period.

In our experience, patients with adequate growth, less than two hospitalizations per year and without symptomatic hypoglycemia are considered to have adequate metabolic control. We do not recommend the administration of fructose and lactose since both sugars cannot be transformed into glucose and consequently produce an increase in lactic acid and metabolic acidosis.[37]

Short stature is common among glycogenosis patients. Good metabolic control can improve growth. In our cohort, only $22.2 \%$ of the patients, 4 of each type, had a height below -2 SDS at the end of the follow-up. Other similar studies have shown $20-40 \%$ of patients with short stature.[38,39] Furthermore, we showed that adherence to treatment significantly improves height.

Hospital admissions for metabolic derangements are triggered by infections and are more frequent in $\mathrm{Ib}$ due to neutrophil dysfunction.[40] Moreover, patients who presented more admissions had a lower height SDS, as we had demonstrated in this study. Due to neutropenia and recurrent infections, they are more exposed to hospitalizations, changes in dietary patterns, and use of medications, which can interfere with adequate diet therapy, causing metabolic decompensation and contributing to growth retardation.

Long-term complications such as obesity ( 7 cases) are linked to the high caloric intake from foods and starch to avoid hypoglycemia. 
Metabolic control has been hypothesized to play a role in adenoma development.[27,41,42] In our cohort, sustained elevations in triglycerides led to early development of adenomas. In 3 out 5 patients, inadequate metabolic control was documented. With strict dietary therapy, adenomas retrograded in two cases, as described in the literature.[27,43] Its prevalence increases after puberty and in some cohorts $75 \%$ develops between the ages of 10 and 20 and decreases after.[44] This may be related to suboptimal metabolic control in this age range and/or the secretion of pubertal hormones. [41] Reported cases of adenomas in GSD I vary in terms of sex, not having a predisposition for any in particular. In our cohort, the female sex was predominated but the number of patients was small. Their development is less frequent in the Ib phenotype. In our experience, 3 of the 5 patients were Ib and they presented at an earlier age. Given that the analyzed population is young (median 9 years) we estimate that the number of affected patients could increases over time.

Renal damage is common in GSDI and tubules and glomerulus may be involved.[45] Nephrolithiasis is associated with hypocitraturia, hypercalciuria but it can also be associated with hyperuricemia and increased uric acid in the urine.[46] Metabolic control itself is not responsible for changes in citrate excretion. It is speculated that they develop distal tubular acidosis that contributes to low urine citrate levels and hypercalciuria.[46] In our population, age of onset was highly variable associated with optimal metabolic control.

Several studies have shown that strict adherence to therapy delays or prevents nephropathy in GSD I. Hyperlipidemia accelerates the glomerular sclerosis process and may be a factor that contributes to renal progression.[47] As demonstrated in our population, sustained elevations in triglycerides led to the early development of nephropathy.[41] In combination with dietary treatment, ACE-inhibitors significantly delayed the progression of renal damage only if therapy was started when glomerular hyperfiltration was detected.[48-50] In our cohort ACE inhibitor therapy was administered in stages of detection of microalbuminuria or even proteinuria. In one case it progressed to proteinuria.

Acute renal failure after immediate liver transplantation is common (25-60\%) and is related to reperfusion injuries due to liver ischemia.[51]

Multiple pre-peri and postoperative factors have been identified.[51] Among the preoperative ones, arterial hypertension, obesity and low renal functional reserve can be identified. All these risk factors can occur in patients with GSD I. Calcineurin inhibitors such as cyclosporine and tacrolimus contribute in the short and long term to the development of nephropathy in transplant patients.[52] The incidence of chronic kidney disease in pediatric patients who have received transplantation liver disease by tacrolimus is $31.4 \%$ and by cyclosporine it is $21 \%$.[53]
These factors may explain the nephropathy developed by two patients after liver transplantation, one two years after and the other, secondary to a clear perioperative injury.

Liver transplantation is the ultimate therapy for hepatic metabolic disease.[53-55] It was indicated to maintain stable metabolic control or because of persistent nodules on the ultrasound image, with an increase in number and /or size, which raised the suspicion of hepatocellular carcinoma. In our Ib patients there was a decreased demand for the granulocyte colony-stimulating factor. Renal disease still develops.

\section{Conclusions}

It seems necessary to raise awareness about the existence of these diseases among neonatologists and pediatricians during the first year of life, as well as to implement measures that improve adherence to treatment.

As we can see in our cohort, with intensive dietary treatment, clinical and biochemical status will improve but cannot be corrected completely in most patients. Growth improves with treatment and this is optimized with adequate adherence. We must take into account that as patients age, more complications will develop. Progressive renal disease and the complications of liver adenomas are likely to be two major causes of morbidity and mortality in these older patients.

\section{Acknowledgements}

The authors would like to thank the multidisciplinary team at the Inborn Errors of Metabolism in Garrahan Hospital with the diagnosis and assistance of the patients. We want to especially thank Dr. Belen Cubria, who helped us with the translation of the manuscript.

\section{Funding}

This research received no specific grant from any funding agency in the public, commercial, or not-for-profit sectors.

\section{Authors' Contributions}

Dr Bindi: Involved in data collection. Involved in design of the project and analysis and interpretation of the data. Drafting the article and critical revision.

Dr Eiroa: Critical revision of the article and approved the final manuscript as submitted.

Dr Crespo: Involved in analysis and data interpretation; Statistical analysis and drafting the molecular analysis.

Dr Martinez: Data collection and data interpretation.

Dr Bay: Involved in design of the project, manuscript writing, critical revision and approved the final manuscript as submitted. 


\section{Declaration of Conflicting Interests}

The Authors declare no conflict of interest.

\section{Supplementary Material}

The following online material is available for this article:

Figure S1 - Box-and-whisker plots representing serum triglyceride concentration before and after treatment divided by a red line. The central box represents the values from the lower to upper quartile ( 25 to 75 percentile). The middle line represents the median. Red braces indicate between which groups significant differences were detected in the post hoc tests. Median and range at each time are indicated below. $\mathrm{p}$ value is indicated.

Figure S2 - Box-and-whisker plots representing serum lactic acid concentration before and after treatment divided by a red line. The central box represents the values from the lower to upper quartile ( 25 to 75 percentile). The middle line represents the median. Red braces indicate between which groups significant differences were detected in the post hoc tests. Median and range at each time are indicated below. $p$ value is indicated.

Table S1 - Clinical and biochemical characteristics associated with liver adenomas.

Table S2 - Clinical and biochemical characteristics associated with nephropathy.

\section{References}

1. Chen Y-T, Kishnani PS, Koeberl D. Glycogen Storage Diseases. In: Valle DL, Antonarakis S, Ballabio A, Beaudet AL, Mitchell GA, eds. The Online Metabolic and Molecular Bases of Inherited Disease. McGraw-Hill Medical; 2009. doi:10.1036/ommbid.380

2. Igarashi $Y$, Otomo H, Narisawa K, Tada K. A new variant of glycogen storage disease type 1: Probably due to a defect in the glucose-6-phosphate transport system. J Inherit Metab Dis. 1979;2(3):45-49. doi:10.1007/bf01801717

3. Veiga-da-Cunha M, Gerin I, Chen YT, et al. The putative glucose 6-phosphate translocase gene is mutated in essentially all cases of glycogen storage disease type I non-a. Eur J Hum Genet. 1999;7(6):717-723. doi:10.1038/ sj.ejhg. 5200366

4. Chou J, Matern D, Mansfield B, Chen Y. Type I Glycogen Storage Diseases: Disorders of the Glucose-6Phosphatase Complex. Curr Mol Med. 2002;2(2):121-143. doi: $10.2174 / 1566524024605798$

5. von Gierke E. Hepato-Nephromegaliaglykogenica. Beitr Pathol. 1976;158(1):94-108. doi:10.1016/s00058165(76)80079-0
6. Cori GT, Cori CF. Glucose-6-phosphatase of the liver in glycogen storage disease. J Biol Chem. 1952;199(2):661-667. http://www.ncbi.nlm.nih.gov/pubmed/13022673

7. Visser G, Rake JP, Fernandes J, et al. Neutropenia, neutrophil dysfunction, and inflammatory bowel disease in glycogen storage disease type Ib: Results of the European study on glycogen storage disease type I. J Pediatr. 2000;137(2):187191. doi:10.1067/mpd.2000.105232

8. Rake J, Visser G, Labrune P, Leonard J, Ullrich K, Smit P. Glycogen storage disease type I: diagnosis, management, clinical course and outcome. Results of the European Study on Glycogen Storage Disease Type I (ESGSD I). Eur J Pediatr. 2002;161:S20-S34. doi:10.1007/s00431-002-0999-4

9. Rake JP, ten Berge AM, Visser G, et al. Glycogen storage disease type Ia: recent experience with mutation analysis, a summary of mutations reported in the literature and a newly developed diagnostic flowchart. Eur J Pediatr. 2000;159(5):322-330. doi:10.1007/s004310051281

10. Matern D, Seydewitz H, Bali D, Lang C, Chen Y-T. Glycogen storage disease type I: diagnosis and phenotype/genotype correlation. Eur J Pediatr. 2002;161:S10-S19. doi:10.1007/ s00431-002-0998-5

11. Weinstein DA, Wolfsdorf JI. Effect of continuous glucose therapy with uncooked cornstarch on the long-term clinical course of type 1a glycogen storage disease. Eur J Pediatr Suppl. 2002;161:35-39. doi:10.1007/bf02679991

12. Visser G, Rake J, Labrune P, et al. Consensus guidelines for management of glycogen storage disease type $1 \mathrm{~b}$ - European Study on Glycogen Storage Disease Type 1. Eur J Pediatr. 2002;161:S120-S123. doi:10.1007/s00431-002-1017-6

13. Kishnani PS, Austin SL, Abdenur JE, et al. Diagnosis and management of glycogen storage disease type I: A practice guideline of the American College of Medical Genetics and Genomics. Genet Med. 2014;16(11):e1. doi:10.1038/ $\operatorname{gim} .2014 .128$

14. Hug G. Glucagon tolerance test in glycogen storage disease. J Pediatr. 1962;60(4):545-549. doi:10.1016/S00223476(62)80116-4

15. Dunger DB, Leonard J V. Value of the glucagon test in screening for hepatic glycogen storage disease. Arch Dis Child. 1982;57(5):384-389. doi:10.1136/adc.57.5.384

16. Richards S, Aziz N, Bale S, et al. Standards and guidelines for the interpretation of sequence variants: A joint consensus recommendation of the American College of Medical Genetics and Genomics and the Association for Molecular Pathology. Genet Med. 2015;17(5):405-424. doi:10.1038/ gim.2015.30

17. World Health Organisation, ed. WHO Child Growth Standards. Geneca: WHO; 2006. https://www.who.int/ publications/i/item/924154693X 
18. Labrune P, Ullrich K, Smit P, Rake J, Visser G, Leonard J. Guidelines for management of glycogen storage disease type I - European Study on Glycogen Storage Disease Type I (ESGSD I). Eur J Pediatr. 2002;161:S112-S119. doi:10.1007/ s00431-002-1016-7

19. Chaudri NA. Adherence to Long-term Therapies Evidence for ActionWorld Health Organization (WHO). Ann Saudi Med. 2004;24(3):221-222. doi:10.5144/02564947.2004.221

20. Marrero JA, Ahn J, Rajender Reddy K, Americal College of Gastroenterology. ACG clinical guideline: the diagnosis and management of focal liver lesions. Am J Gastroenterol. 2014;109(9):1328-1347. doi:10.1038/ajg.2014.213

21. Davoudi-Kiakalayeh A, Mohammadi R, Pourfathollah AA, Siery Z, Davoudi-Kiakalayeh S. Simplified Algorithm for Evaluation of Proteinuria in Clinical Practice: How should A Clinician Approach? Int J Prev Med. 2017;8:101. doi:10.4103/ijpvm.ijpvm

22. Chou JY, Jun HS, Mansfield BC. Glycogen storage disease type I and G6Pase- $\beta$ deficiency: etiology and therapy. Nat Publ Gr. 2010;6(12):676-688. doi:10.1038/nrendo.2010.189

23. Harris DL, Weston PJ, Harding JE. Incidence of neonatal hypoglycemia in babies identified as at risk. J Pediatr. 2012;161(5):787-791. doi:10.1016/j.jpeds.2012.05.022

24. Dublin G, Wendel U, Schwahn B. Type I glycogen storage disease: favourable outcome on a strict management regimen avoiding increased lactate production during childhood and adolescence. Eur J Pediatr. 2002;161:S40-S45. doi:10.1007/s00431-002-1001-1

25. Fernandes J, Berrge R, Smit GPA. Lactate as a cerebral metabolic fuel for glucose 6 phosphatase deficient children. Pediatr Res. 1984;18(4):335-339. doi:10.1203/00006450198404000-00006

26. Derks TGJ, van Rijn M. Lipids in hepatic glycogen storage diseases: pathophysiology, monitoring of dietary management and future directions. J Inherit Metab Dis. 2015;38(3):537-543. doi:10.1007/s10545-015-9811-2

27. Beegle RD, Brown LM, Weinstein DA. Regression of hepatocellular adenomas with strict dietary therapy in patients with glycogen storage disease type I. JIMD Rep. 2015;18:23-32. doi:10.1007/8904_2014_344

28. Melis D, Parenti G, Dell Casa R, et al. Brain damage in glycogen storage disease type I. J Pediatr. 2004;144(5):637642. doi:10.1016/j.jpeds.2004.02.033

29. Göğüş S, Koçak N, Ciliv G, et al. Histologic Features of the Liver in Type Ia Glycogen Storage Disease: Comparative Study between Different Age Groups and Consecutive Biopsies. Pediatr Dev Pathol. 2002;5(3):299-304. doi:10.1007/s10024-001-0139-6
30. Beyzaei Z, Geramizadeh B. Molecular diagnosis of glycogen storage disease type I: A review. EXCLI J. 2019;18:30-46. doi:10.17179/excli2018-1877

31. Chou JY, Mansfield BC. Mutations in the glucose-6phosphatase- $\alpha$ (G6PC) gene that cause type Ia glycogen storage disease. Hum Mutat. 2008;29(7):921-930. doi:10.1002/humu.20772

32. Angaroni CJ, De Kremer RD, Argaraña CE, et al. Glycogen storage disease type Ia in Argentina: Two novel glucose6-phosphatase mutations affecting protein stability. Mol Genet Metab. 2004;83(3):276-279. doi:10.1016/j. ymgme.2004.06.010

33. Sperb-Ludwig F, Pinheiro FC, Soares MB, et al. Glycogen storage disease: Twenty-seven new variants in a cohort of 125 patients. Mol Genet Genomic Med. 2019;7:e877. doi:10.1002/mgg3.877

34. Vega AI, Medrano C, Navarrete R, et al. Molecular diagnosis of glycogen storage disease and disorders with overlapping clinical symptoms by massive parallel sequencing. Genet Med. 2016;18(10):1037-1043. doi:10.1038/gim.2015.217

35. Huidekoper HH, Ackermans MT, Ruiter AFC, Sauerwein HP, Wijburg FA. Endogenous glucose production from infancy to adulthood: A non-linear regression model. Arch Dis Child Educ Pract Ed. 2014;99(12):1098-1102. doi:10.1136/archdischild-2013-305718

36. Wolfsdorf JI, Keller RJ, Landy H, Crigier JF. Glucose therapy for glycogenosis type 1 in infants: Comparison of intermittent uncooked cornstarch and continuous overnight glucose feedings. J Pediatr. 1990;117(3):384391. doi:10.1016/S0022-3476(05)81077-7

37. FERNANDES J. the Effect of Disaccharides on the Hyperlactacidaemia of Glucose-6-PhosphataseDeficient Children. Acta Podiatrica. 1974;63(5):695-698. doi:10.1111/j.1651-2227.1974.tb16992.x

38. Santos BL, de Souza CF, Schuler-Faccini L, et al. Glycogen storage disease typeI: clinical and laboratory profile. J Pediatr (Rio J). 2014;90:572-579. doi:10.1016/j.jped.2014.02.005

39. Jorge NB, Tommaso AMA, Hessel G. Anthropometric and dietary assessment of patients with glycogenosis Type I. Rev Paul Pediatr. 2021;39: e2020046. doi:10.1590/19840462/2021/39/2020046

40. Visser G, Rake JP, Fernandes J, et al. Neutropenia, neutrophil dysfunction, and inflammatory bowel disease in glycogen storage disease type Ib: Results of the European study on glycogen storage disease type I. J Pediatr. 2000;137(2): 187-191. doi:10.1067/mpd.2000.105232

41. Wang DQ, Fiske LM, Carreras CT, Weinstein DA. Natural history of hepatocellular adenoma formation in glycogen storage disease Type I. J Pediatr. 2011;159(3):442-446. doi:10.1016/j.jpeds.2011.02.031 
42. Di Rocco M, Calevo MG, Taro' M, Melis D, Allegri AEM, Parenti G. Hepatocellular adenoma and metabolic balance in patients with type Ia glycogen storage disease. Mol Genet Metab. 2008;93(4):398-402. doi:10.1016/j. ymgme.2007.10.134

43. Wang DQ, Carreras CT, Fiske LM, et al. Characterization and pathogenesis of anemia in glycogen storage disease type Ia and Ib. Genet Med. 2012;14(9):795-799. doi:10.1038/ gim.2012.41

44. Rake J, Visser G, Labrune P, Leonard J, Ullrich K, Smit P. Glycogen storage disease type I: diagnosis, management, clinical course and outcome. Results of the European Study on Glycogen Storage Disease Type I (ESGSD I). Eur J Pediatr. 2002;161:S20-S34. doi:10.1007/s00431-002-0999-4

45. Chen YT. Type I glycogen storage disease: Kidney involvement, pathogenesis and its treatment. Pediatr Nephrol. 1991;5(1):71-76. doi:10.1007/BF00852851

46. Weinstein DA, Somers MJG, Wolfsdorf JI. Decrease urinary citrate excretion in type 1a glycogen storage disease. J Pediatr. 2001;138(3):378-382. doi:10.1067/ mpd.2001.111322

47. Wolfsdorf JI, Laffel LMB, Crigler JF. Metabolic control and renal dysfunction in type I glycogen storage disease. J Inherit Metab Dis. 1997;20(4):559-568. doi:10.1023/A:1005346824368

48. Melis D, Cozzolino M, Minopoli G, et al. Progression of renal damage in glycogen storage disease type $\mathrm{i}$ is associated to hyperlipidemia: A multicenter prospective Italian study. J Pediatr. 2015;166(4):1079-1082. doi:10.1016/j. jpeds.2014.12.015
49. Okechuku GO, Shoemaker LR, Dambska M, Brown LM, Mathew J, Weinstein DA. Tight metabolic control plus ACE inhibitor therapy improves GSD I nephropathy. J Inherit Metab Dis. 2017;40(5):703-708. doi:10.1007/s10545-0170054-2

50. Melis D, Parenti G, Gatti R, et al. Efficacy of ACE-inhibitor therapy on renal disease in glycogen storage disease type 1 : A multicentre retrospective study. Clin Endocrinol (Oxf). 2005;63(1):19-25. doi:10.1111/j.1365-2265.2005.02292.x

51. Lacquaniti A, Campo S, Casuscelli Di Tocco T, et al. Acute and chronic kidney disease after pediatric liver transplantation: An underestimated problem. Clin Transplant. 2020;34:e14082. doi:10.1111/ctr.14082

52. Matloff RG, Arnon R, Saland JM. The kidney in pediatric liver transplantation: An updated perspective. Pediatr Transplant. 2012;16(8):818-828. doi:10.1111/petr.12006

53. O'Riordan A, Wong V, McCormick PA, Hegarty JE, Watson AJ. Chronic kidney disease post-liver transplantation. Nephrol Dial Transplant. 2006;21(9):2630-2636. doi:10.1093/ndt/gfl247

54. Boers SJB, Visser G, Smit PGPA, Fuchs SA. Liver transplantation in glycogen storage disease type i. Orphanet J Rare Dis. 2014;9:47. doi:10.1186/1750-1172-9-47

55. Labrune P. Glycogen storage disease type I : indications for liver and / or kidney transplantation. Eur J Pediatr. 2002;161:S53-S55. doi:10.1007/s00431-002-1004-y 